\title{
ASSOCIATION OF DYSLIPIDEMIA WITH ANXIETY AND DEPRESSION IN PATIENTS OF POLYCYSTIC OVARIAN SYNDROME
}

\author{
Rozina Habib ${ }^{1,2,3 凶}$, Shafiq-Ur-Rahman ${ }^{3}$, Tariq Zubairr, ${ }^{1,2}$, Musaira Tariq ${ }^{3}$
}

\section{ABSTRACT}

OBJECTIVE: To find-out the association of dyslipidemia with anxiety and depression in patients with polycystic ovarian syndrome (PCOS).

METHODS: This descriptive cross-sectional study was conducted at Mardan Medical Complex, Mardan, Pakistan from December-2019 to March-2020. One hundred \& forty diagnosed cases of PCOS, ranging in age from 20-40 years, were selected through purposive sampling. Anxiety and depression were calculated using hospital anxiety and depression scale (HADS) score. Total cholesterol (TC), triglycerides, low-density-lipoproteins (LDL), high-density-lipoproteins (HDL) and testosterone were tested through fasting blood samples.

RESULTS: Anxiety and depression were documented in 102 (72.9\%) \& 99 (70.7\%) cases respectively. Primary infertility, oligomenorrhoea, Hirsutism \& acne were present in 69 (49.3\%), III (73.5\%), 8I (57.9\%) and 55 (39.3\%) patients respectively. Twenty-two (15.7\%) patients were overweight/obese. All patients had raised testosterone levels and polycystic ovaries on ultrasound. Raised triglyceride levels $(\geq 150 \mathrm{mg} / \mathrm{dl})$, Low levels of $\mathrm{HDL}(<60 \mathrm{mg} / \mathrm{dl})$, raised levels of LDL $(\geq 130 \mathrm{mg} / \mathrm{dl})$, raised cholesterol levels $(\geq 200 \mathrm{mg} / \mathrm{dl})$ were reported in $71 / 99$ (7I.7\%), 56/99 (56.6\%), 38/99 (38.4\%) \& 10/99 (10.2\%) cases with depression as compared to $27 / 4$ I (65.9\%), I3/4I (3I.7\%), 2I/4I (5I.2\%) \& I $4 / 4 I(34.1 \%)$ non-depressed patients respectively. Similarly raised triglyceride levels, low levels of HDL, raised levels of LDL, raised cholesterol levels were reported in 73/102 (7I.6\%), 58/1 02 (56.9\%), 40/102 (39.2\%) \& $12 / 102$ (I I.76\%) cases with anxiety as compared to $25 / 38$ (65.8\%), I I/38 (28.9\%), $19 / 38(50 \%)$ and $12 / 38(31.6 \%)$ patients without anxiety respectively.

CONCLUSION: Dyslipidemia, anxiety and depression are very common in PCOS. Dyslipidemia is associated with anxiety and depression in $\mathrm{PCOS}$ patients.

KEY WORDS: Polycystic Ovary Syndrome (MeSH); Anxiety (MeSH); Depression (MeSH); Dyslipidemias (MeSH); Triglycerides (MeSH); Cholesterol (MeSH); Lipids (MeSH); Hospital Anxiety and Depression Score (Non-MeSH); Hirsutism (MeSH); Obesity (MeSH).

THIS ARTICLE MAY BE CITED AS: Habib R, Shafiq-Ur-Rahman, Zubair T, Tariq M. Association of dyslipidemia with anxiety and depression in patients of polycystic ovarian syndrome. Khyber Med Univ J 2020;13(2):113-7. https://doi.org/l0.35845/kmuj.2021.21298

\section{INTRODUCTION}

$\mathrm{P}$ olycystic ovarian syndrome (PCOS) is a heterogenic endocrine disorder presenting with menstrual irregularities, infertility and features of hyperandrogenism i.e., acne, hirsutism and alopecia and metabolic syndrome.' PCOS affects 6$18 \%$ of women in reproductive age group. This syndrome is primarily considered as a reproductive and metabolic disorder, but these patients also show higher rates of psychological morbidities. ${ }^{2}$
Cinar et al, has reported depression rates between I 4 and $64 \%$ in PCOS patients. ${ }^{3}$ Such a wide range of prevalence might be due to reasons like different sociocultural populations, ethnic differences and variations in methodologies for depression screening. ${ }^{3}$ PCOS women also show increased prevalence of anxiety than in general population ( $3457 \%$ versus $18 \%$ ). ${ }^{3}$ The main factors responsible for such high rates of anxiety disorders may be acne, hirsutism and obesity. ${ }^{3}$ PCOS patients have $30-40 \%$ risk of developing insulin resistance, impaired glucose tolerance and Type 2
I: Gajju Khan Medical College, Swabi, Pakistan.

2: Bacha Khan Medical College, Mardan Medical Complex, Mardan, Pakistan.

3: Khyber Medical College, Peshawar, Pakistan.

Contact \# : +92-313-0877000

Email冈: rozinatariq157।@gmail.com

Date Submitted: February 14,2021

Date Revised: June 26, 2021

Date Accepted: June 28, 2021

diabetes mellitus. ${ }^{3}$ Other risk factors for cardiovascular disease (CVD) such as hypertension, dyslipidemia, atherosclerosis and endothelial dysfunction are also reported to be associated with PCOS. ${ }^{3}$ In US, $70 \%$ of PCOS women have dyslipidemia showing different patterns. High triglycerides (TG) and low high-density lipoproteins (HDL) are common in PCOS women while high values of low-density lipoproteins (LDL) may be related to hyperandrogenism. ${ }^{4}$

There is scarce available data (both local and international) on association of dyslipidemia with anxiety and depression in PCOS patients. So, the present study was conducted to find out frequency of anxiety and depression in PCOS patients and to look for association of dyslipidemia with anxiety and depression in these patients in our local setup. We hope that general practitioners and gynecologists shall focus attention on psychological assessment and lipid measurement in this group of patients, in order to categorize them for optimal management.

\section{METHODS}

This descriptive cross-sectional study was done on young women of reproductive age coming to outpatient Department of Gynecology and Obstetrics at Mardan Medical Complex, Mardan, Khyber Pakhtunkhwa- Pakistan. Sample size was calculated using the following formula, $n=\frac{z^{(p \times \times)}}{e^{2}}$ Where prevalence of PCOS is taken as 10 in 100. Inclusion criteria were women, both married and unmarried, with age of 2040 years having polycystic ovarian syndrome of any duration while pregnant 
TABLE I: DEMOGRAPHIC AND CLINICAL CHARACTERISTIC OF STUDY POPULATION $(\mathrm{N}=\mid \mathbf{4 0})$

\begin{tabular}{|c|c|c|c|}
\hline Variables & Characteristic & Frequency & Percentage \\
\hline \multirow{2}{*}{ Marital status } & Married & 104 & 74.3 \\
\hline & Un-married & 36 & 25.7 \\
\hline \multirow{3}{*}{$\begin{array}{l}\text { Menstrual } \\
\text { irregularities }\end{array}$} & Oligomenorrhoea & 111 & 79.3 \\
\hline & Polymenorrhoea & 25 & 17.9 \\
\hline & Normal cycle & 4 & 2.9 \\
\hline \multirow{2}{*}{$\begin{array}{l}\text { Clinical Hyper- } \\
\text { Androgenism }\end{array}$} & Hirsutism & 81 & 57.9 \\
\hline & Acne & 55 & 39.3 \\
\hline $\begin{array}{l}\text { Biochemical Hyper - } \\
\text { Androgenism }\end{array}$ & Raised Serum testosterone & 140 & $100 \%$ \\
\hline \multirow{2}{*}{ Infertility } & Primary & 69 & 49.3 \\
\hline & Secondary & 33 & 23.6 \\
\hline \multirow{3}{*}{$\begin{array}{l}\text { Body Mass Index } \\
\text { (BMI) }\end{array}$} & Under-weight & 36 & $25.7 \%$ \\
\hline & Normal & 82 & $58.6 \%$ \\
\hline & Overweight/Obese & 22 & $15.7 \%$ \\
\hline \multirow{3}{*}{ Pelvic Ultrasound } & Right ovary cystic & 42 & 30.0 \\
\hline & Left ovary cystic & 50 & 35.7 \\
\hline & Both ovaries cystic & 48 & 34.3 \\
\hline \multirow{2}{*}{ Psychological stress } & Anxiety & 102 & 72.9 \\
\hline & Depression & 99 & 70.7 \\
\hline \multirow{3}{*}{ Triglycerides } & Desirable $(<150 \mathrm{mg} / \mathrm{dl})$ & 42 & 30 \\
\hline & Borderline risk $(150-199 \mathrm{mg} / \mathrm{dl})$ & 37 & 26.4 \\
\hline & High-risk ( $\geq 200 \mathrm{mg} / \mathrm{dl})$ & 61 & 43.6 \\
\hline \multirow{3}{*}{$\begin{array}{l}\text { High Density } \\
\text { Lipoproteins (HDL) }\end{array}$} & Desirable $(>60 \mathrm{mg} / \mathrm{dl})$ & 71 & 50.7 \\
\hline & Borderline risk (35-59 mg/dl) & 57 & 40.7 \\
\hline & High risk $(<35 \mathrm{mg} / \mathrm{dl})$ & 12 & 8.6 \\
\hline \multirow{3}{*}{$\begin{array}{l}\text { Low Density } \\
\text { Lipoproteins (LDL) }\end{array}$} & Desirable $(60-129 \mathrm{mg} / \mathrm{dl})$ & 81 & 57.9 \\
\hline & Borderline risk (130-159 mg/dl) & 56 & 40.0 \\
\hline & High risk $(\geq 160 \mathrm{mg} / \mathrm{dl})$ & 3 & 2.1 \\
\hline \multirow{3}{*}{ Total Cholesterol } & Desirable $(<200 \mathrm{mg} / \mathrm{dl})$ & 116 & 82.9 \\
\hline & Borderline risk $(200-239 \mathrm{mg} / \mathrm{dl})$ & 19 & 13.6 \\
\hline & High risk $(\geq 240 \mathrm{mg} / \mathrm{dl})$ & 5 & 3.6 \\
\hline
\end{tabular}

women, patients with known endocrine disorders like Cushing syndrome, hyperprolactinemia, diabetes and hypertension and those taking oral contraceptive pills were excluded from the study.

Patients were diagnosed as PCOS according to Rotterdam criteria ${ }^{5}$ applied on suspected cases using purposive sampling technique. Rotterdam criteria for the diagnosis of PCOS is the presence of at least two out of following three features:

I. Oligo-ovulation or anovulation on the basis of history of oligomenorrhoea/ polymenorrhoea

2. Clinical hyperandrogenism on the basis of acne, hirsutism and alopecia or biochemical hyperandrogenism on the basis of raised free testosterone levels

3. Polycystic ovaries on the basis of ultrasonic findings of 10 or more antral follicles in each ovary.

After taking informed consent, relevant demographic, anthropometric, clinical and PCOS related data were collected and entered on a specially designed proforma which included information like name, age, weight, height, marital status, menstrual history, present and past medical history and drug history. Body mass index (BMI) was calculated as weight in $\mathrm{kg}$ divided by height per square meter $\left(\mathrm{kg} / \mathrm{m}^{2}\right)$ with a cut off value of $\geq 24$ considered as overweight or obese. ${ }^{6}$ Clinical examination findings like blood pressure, any systemic illness, presence of acne, hirsutism and male pattern alopecia and ultrasound findings of ovarian antral follicles were also noted.

Hospital Anxiety and Depression Scale (HADS) score for each patient was calculated for determination of anxiety and depression. HADS is a 14 items questionnaire; seven are related to anxiety and seven to depression symptoms. Each question has marks of $0 \mathrm{I}, 2$ and 3 . Score for each category can range from 0 to 21 . A score of 7 or below shows no anxiety and depression while a score of 8 and above indicates the presence of anxiety and depression. ${ }^{7}$ A validated Urdu version was utilized in the study. ${ }^{8}$
All patients were tested for fasting serum lipid profile and free testosterone levels. Different componenets of fasting lipids were checked by using the following principles; Total cholesterol level (TC) was determined after enzymatic hydrolysis and oxidation. Determination of TG after enzymatic splitting with lipoprotien lipase was done. HDL, which remain in the supernatant after centrifugation was enzymatically determined by the DIALAB cholestrol CHOD-PAP reagent. LDL was measured from measured values of TC, TG and HDL according to following relationship among them; LDL = TC HDL (TG/5). Values of TC, LDL and TG below which they were considerd normal were taken as; $200 \mathrm{mg} / \mathrm{dl}, 130 \mathrm{mg} / \mathrm{dl}$ and $150 \mathrm{mg} / \mathrm{dl}$ respectively while cut off value for HDL above which it was considered normal was taken as $60 \mathrm{mg} / \mathrm{dl} .^{10}$

Testosterone was measured by the Testosterone Chemiluminescence Immunoassay." It is based on the principle of competitive binding between testosterone in the test specimen and testosterone-HRP conjugate for a constant amount of rabbit anti-testosterone. Cutoff value of total testosterone was taken as 0.9 $\eta \mathrm{g} / \mathrm{ml}$. All the collected data was entered into the proforma. Thereafter the data was recorded and analyzed using Statistical Package for Social Sciences (SPSS) version 23.

For both anxiety and depression separately, patients were divided into two sets of two groups each; that is PCOS women with anxiety and without anxiety and PCOS women with depression and without depression. Association was assessed by comparing the two groups in each set for presence of all four components of dyslipidemia by using chi-square test $\left(x^{2}\right)$ with a $p$ value of $<0.05$ considered as statistically significant. Analyzed Data is presented in the form of tables and charts.

\section{RESULTS}

Out of I 40 women, 104 (74.3\%) were married. All patients were ranging in age from 20-40 years with menarche at the age of $12-15$ years. Primary infertility was present in $69(49.3 \%)$ and oligomenorrhoea in III (73.5\%). 
TABLE II:COMPARISON OF LIPID PROFILE IN POLYCYSTIC OVARIAN SYNDROME PATIENTS WITH AND WITHOUT DEPRESSION

\begin{tabular}{|c|c|c|c|c|c|}
\hline & & \multicolumn{3}{|c|}{ Depression } & \multirow[b]{2}{*}{$\begin{array}{l}\text { Chi } \\
\text { Square }\end{array}$} \\
\hline & & $\begin{array}{l}\text { Present } \\
(n=99)\end{array}$ & $\begin{array}{c}\text { Not present } \\
(n=4 I)\end{array}$ & Total $(n=140)$ & \\
\hline \multirow{3}{*}{ Triglycerides } & Desirable $(<I 50 \mathrm{mg} / \mathrm{dl})$ & $28(28.3 \%)$ & $14(34.1 \%)$ & $42(30 \%)$ & \multirow{3}{*}{0.078} \\
\hline & Borderline risk (150-199 mg/dl) & $27(27.3 \%)$ & $10(24.4 \%)$ & $37(26.4 \%)$ & \\
\hline & High-risk $(\geq 200 \mathrm{mg} / \mathrm{dl})$ & $44(44.4 \%)$ & $17(41.9 \%)$ & $61(43.6 \%)$ & \\
\hline \multirow{3}{*}{$\begin{array}{l}\text { High Density } \\
\text { Lipoproteins } \\
\text { (HDL) }\end{array}$} & Desirable $(>60 \mathrm{mg} / \mathrm{dl})$ & $43(43.4 \%)$ & $28(68.3 \%)$ & $71(50.7 \%)$ & \multirow{3}{*}{$0.010^{*}$} \\
\hline & Borderline risk $(35-59 \mathrm{mg} / \mathrm{dl})$ & $51(51.5 \%)$ & $6(14.6 \%)$ & $57(40.7 \%)$ & \\
\hline & High risk (<35mg/dl) & $5(5.1 \%)$ & $7(17.1 \%)$ & $12(8.6 \%)$ & \\
\hline \multirow{3}{*}{$\begin{array}{l}\text { Low Density } \\
\text { Lipoproteins } \\
\text { (LDL) }\end{array}$} & Desirable $(60-129 \mathrm{mg} / \mathrm{dl})$ & $61(61.89 \%)$ & $20(48.8 \%)$ & $81(57.9 \%)$ & \multirow{3}{*}{0.143} \\
\hline & Borderline risk $(130-159 \mathrm{mg} / \mathrm{dl})$ & $35(35.4 \%)$ & $21(51.2 \%)$ & $56(40.0 \%)$ & \\
\hline & High risk $\geq 160 \mathrm{mg} / \mathrm{dl})$ & $3(3.09 \%)$ & $0(0 \%)$ & $3(2.1 \%)$ & \\
\hline \multirow{3}{*}{ Total Cholesterol } & Desirable $(<200 \mathrm{mg} / \mathrm{dl})$ & $89(89.8 \%)$ & $27(65.9 \%)$ & $116(82.9 \%)$ & \multirow{3}{*}{$0.010^{*}$} \\
\hline & Borderline risk $(200-239 \mathrm{mg} / \mathrm{dl})$ & $5(5.1 \%)$ & $14(34.1 \%)$ & $19(13.6 \%)$ & \\
\hline & High risk $(\geq 240 \mathrm{mg} / \mathrm{dl})$ & $5(5.1 \%)$ & $0(0 \%)$ & $5(3.6 \%)$ & \\
\hline
\end{tabular}

Hirsutism was present in 81 (57.9\%) while $55(39.3 \%)$ patients had acne. Twenty-two (15.7\%) patients were overweight/obese. All patients had raised total testosterone levels and had polycystic ovaries on ultrasound.

Anxiety was present in 102 (72.9\%) while depression in $99(70.7 \%)$. Out of 140 patients with PCOS, desirable levels of Triglycerides $(<150 \mathrm{mg} / \mathrm{dl})$, HDL (>60 mg /dl), LDL < $130 \mathrm{mg} / \mathrm{dl})$ \& Total Cholesterol $(<200 \mathrm{mg} / \mathrm{dl})$ were observed in 42 (30\%), 7I (50.7\%), 8I $(57.9 \%)$ and $116(82.9 \%)$ cases respectively. Cholesterol was raised in 25 (17.2\%), LDL was raised in 59 (42.1\%), HDL was decreased in 69 (49.3\%) and TG was raised in 98 (70\%) patients (Table I).

Comparison of lipid profile in PCOS patients with and without depression is given in Table II. Raised triglyceride levels $(\geq 150 \mathrm{mg} / \mathrm{dl})$ were observed in $71 / 99(71.7 \%)$ of depressed patients as compared to $27 / 4$ I (65.9\%) patients without depression $(p>0.05)$. Low levels of $\mathrm{HDL}(<60 \mathrm{mg} / \mathrm{dl})$ were found in $56 / 99(56.6 \%)$ depressed patients and |3/4| (31.7\%) non-depressed patients $(p<0.05)$. Raised levels of LDL $(\geq 130$ $\mathrm{mg} / \mathrm{dl})$ were found in $38 / 99(38.4 \%)$ patients with depression as compared to $2 \mathrm{I} / 4 \mathrm{I}$ (5I.2\%) non-depressed patients. Raised cholesterol levels $(\geq 200 \mathrm{mg} / \mathrm{dl})$ were found in $10 / 99$ $(10.2 \%)$ of depressed patients and |4/4I(34.1\%) non-depressed patients $(\mathrm{p}<0.05)$.

Comparison of lipid profile in PCOS patients with and without anxiety is given in Table III. Raised triglyceride levels $(\geq 150 \mathrm{mg} / \mathrm{dl})$ were present in $73 / 102(71.6 \%)$ patients having anxiety as compared to $25 / 38(65.8 \%)$ patients without anxiety $(p>0.05)$. Low levels of $\mathrm{HDL}(<60 \mathrm{mg} / \mathrm{dl})$ were found in 58/102 $(56.9 \%)$ patients having anxiety and II/38 (28.9\%) patients having no anxiety $(p<0.05)$. Raised levels of LDL $(\geq 130 \mathrm{mg} / \mathrm{dl})$ were found in $40 / 102$ (39.2\%) patients having anxiety as compared to $19 / 38$ (50\%) patients having no anxiety $(P>0.05)$. Raised total cholesterol levels $(\geq 200 \mathrm{mg} / \mathrm{dl})$ were found in $12 / 102$ (1I.76\%) patients having anxiety and $12 / 38$ (31.6\%) patients having no anxiety $(\mathrm{p}<0.05)$.

\section{DISCUSSION}

This study was conducted to determine the frequency of depression and anxiety in $\mathrm{PCOS}$ patients and the association of anxiety and depression with dyslipidemia. A total of I 40 patients were selected on the basis of clinical and biochemical confirmation of PCOS. Anxiety and depression were very common finding among these patients. The causes of anxiety and depression were menstrual irregularities, hirsutism, infertility and obesity. Dyslipidemia was associated with Anxiety and depression in PCOS patients. Raised levels of testosterone were present in all patients with PCOS.

Zehra S et al, conducted a cross sectional study in Pakistan. Their study stated that anxiety and depression scores were high in PCOS patients compared to control. In their study, anxiety was present in $42.6 \%$ while depression was present in $31.1 \%$ and $20 \%$ of the study group had both anxiety and depression. They stated that anxiety and depression levels were more prevalent in PCOS patients and are related with acne, hirsutism, obesity, menstrual irregularities, infertility, and dyslipidemia and insulin resistance. Their findings supported our findings of anxiety and depression and their association with dyslipidemia in PCOS patients.'

In another cross-sectional study performed by Enjezab et al, $64.5 \%$ of the PCOS patients were found to have depression, similar to our study. They found no correlation of depression with $\mathrm{BMI}, \mathrm{IR}$ and total testosterone levels. In our study we also did not find correlation between anxiety, depression, BMI and IR but our study show that all the patients have raised testosterone level which is responsible androgenic features of PCOS. ${ }^{13}$ In another cross-sectional study performed by Xiaoli Chen et al, BMI levels of PCOS patients were compared with controls. According to WHO, generally Asian have higher body fat than white population of the same age, sex and BMI. They stated that waist hip ratio, serum insulin and TG were positively correlated with $\mathrm{BMI}$ in PCOS patients. With increasing BMI, the prevalence of fasting insulin, central obesity and dyslipidemia also increases. They found increased levels of TG, fasting insulin and fasting glucose in the study group. Thus, the risk of having metabolic syndrome is higher in PCOS patients compared with control. They also showed that insulin levels were positively correlated with BMI. And BMI is correlated positively with TG and negatively with HDL. ${ }^{14}$ Our study shows that $15.7 \%$ of the selected patients had raised BMI (obese/overweight) which may because of small sample size and 
ASSOCIATION OF DYSLIPIDEMIA WITH ANXIETY AND DEPRESSION IN PATIENTS OF POLYCYSTIC OVARIAN SYNDROME

TABLE III: COMPARISON OF LIPID PROFILE IN POLYCYSTIC OVARIAN SYNDROME PATIENTS WITH AND WITHOUT ANXIETY

\begin{tabular}{|c|c|c|c|c|c|}
\hline \multirow{2}{*}{\multicolumn{2}{|c|}{ Parameters }} & \multicolumn{3}{|c|}{ Anxiety } & \multirow{2}{*}{ Chi square } \\
\hline & & \multirow{2}{*}{$\begin{array}{c}\text { Present }(\mathbf{n}=102) \\
29(28.4 \%)\end{array}$} & \multirow{2}{*}{\begin{tabular}{|c|} 
Not Present $(\mathbf{n}=\mathbf{3 8})$ \\
$13(34.2 \%)$
\end{tabular}} & \multirow{2}{*}{\begin{tabular}{|c|} 
Total $(n=140)$ \\
$42(30 \%)$
\end{tabular}} & \\
\hline \multirow{3}{*}{ Triglycerides } & Desirable (<I50mg/dl) & & & & \multirow{3}{*}{0.075} \\
\hline & Borderline risk (I50-199mg/dl) & $27(26.5 \%)$ & $10(26.3 \%)$ & $37(26.4 \%)$ & \\
\hline & High-risk ( $\geq 200 \mathrm{mg} / \mathrm{dl})$ & $46(45.1 \%)$ & $15(39.5 \%)$ & $61(43.6 \%)$ & \\
\hline \multirow{3}{*}{$\begin{array}{l}\text { High Density } \\
\text { Lipoproteins (HDL) }\end{array}$} & Desirable $(>60 \mathrm{mg} / \mathrm{dl})$ & $44(43.1 \%)$ & $27(71.1 \%)$ & $71(50.7 \%)$ & \multirow{3}{*}{$0.011^{*}$} \\
\hline & Borderline risk (35 - 59mg/dl) & $51(50 \%)$ & $6(15.8 \%)$ & $57(40.7 \%)$ & \\
\hline & High risk $(<35 \mathrm{mg} / \mathrm{dl})$ & $7(6.9 \%$ & $5(13.2 \%)$ & $12(8.6 \%)$ & \\
\hline \multirow{3}{*}{$\begin{array}{l}\text { Low Density } \\
\text { Lipoproteins (LDL) }\end{array}$} & Desirable (60- $129 \mathrm{mg} / \mathrm{dl})$ & $62(60.8 \%)$ & $19(50 \%)$ & $81(57.9 \%)$ & \multirow{3}{*}{0.051} \\
\hline & Borderline risk (I30- $\mid 59 \mathrm{mg} / \mathrm{dl})$ & $38(37.3 \%)$ & $18(47.4 \%)$ & $56(40 \%)$ & \\
\hline & High risk $(\geq 160 \mathrm{mg} / \mathrm{dl})$ & $2(2 \%)$ & I (2\%) & $3(2.1 \%)$ & \\
\hline \multirow{3}{*}{ Total Cholesterol } & Desirable $(<200 \mathrm{mg} / \mathrm{dl})$ & $90(88.2 \%)$ & $26(68.4 \%)$ & $116(82.9 \%)$ & \multirow{3}{*}{$0.019^{*}$} \\
\hline & Borderline risk (200-239mg/dl) & $9(8.8 \%)$ & $10(26.3 \%)$ & $19(13.6 \%)$ & \\
\hline & High risk ( $\geq 240 \mathrm{mg} / \mathrm{dl})$ & $3(2.9 \%)$ & $2(5.3 \%)$ & $5(3.5 \%)$ & \\
\hline
\end{tabular}

random selection, variability in ethnicity and other socio demographic variations.

Moreover, in our study correlation of BMI and dyslipidemia was not determined. A classic lipid profile with significantly elevated TG, raised cholesterol, raised LDL and decreased serum HDL levels was noted in the study by Bilal et al. ${ }^{15}$ Same pattern of dyslipidemia was noted in our study. Hence, in PCOS patients, to assess cardiovascular risk factors, lipid profile should be essential part of investigation. These findings were supported by other studies on national and international level. Nesecinar et al, also showed significant correlation between anxiety, depression and metabolic parameters including dyslipidemia. ${ }^{3}$

The AE-PCOS society created a panel which suggested that weight loss was associated with improvement in dyslipidemia and depression. ${ }^{16}$

\section{CONCLUSION}

This study showed that dyslipidemia including high cholesterol, LDL, low HDL and raised TG levels are common in PCOS patients. Anxiety and depression are also very common and present in almost two third of patients with PCOS. There is a strong relationship of dyslipidemia with anxiety and depression in these patients. Further research is recommended to explore the relationship of dyslipidemia with anxiety and depression in patients with PCOS.

\section{RECOMMENDATIONS}

PCOS should be diagnosed as early as possible. Psychological assessment along with dyslipidemia screening of all the patients with PCOS should be conducted for their timely management to prevent CVD. Awareness and educational programs may be arranged for young adult females at school and college levels to educate them about the squeal associated with PCOS. Dyslipidemia associated with PCOS is an important risk factor for cardiovascular diseases and addressing these risks by lifestyle modification, psychiatric counseling and medication will improve the cardiovascular outcomes in $\mathrm{PCOS}$ patients.

\section{LIMITATIONS}

This was a cross-sectional study where limited number of patients were selected. There was no control group. Other CVD risk factors were not taken into consideration. A prospective cohort study will give a more in-depth view and knowledge of CVD risk factors and their association with anxiety and depression in PCOS patients.

\section{REFERENCES}

I. Sulaiman MA, Al-Farsi YM, AlKhaduri MM, Waly MI, Saleh J, AlAdawi. Psychological burden among women with polycystic ovarian syndrome in Oman: a case-control study. Int J Womens Health 2017;9: 897-904. https://doi.org//0.2147/ IJWH.SI45383.

2. Karjula S, Morin-Papunen L, Franks S, Auvinen J, Jarvelin MR, Tapanainen JS, et al. Population-based data at ages $3 \mathrm{I}$ and 46 show decreased HRQoL and life satisfaction in women with PCOS symptoms. J Clin Endocrinol Metab 2020; 105(6): 1814-26. https:// doi.org/10.1210/clinem/dgz256

3. Cinar N, Kizilarslanoglu MC, Harmanci A, Aksoy DY, Bozdag G,
Demir B, et al. Depression, anxiety and cardiometabolic risk in polycystic ovary syndrome. Hum Reprod 20II;26(I2):3339-45. https:// doi.org/10.1093/humrep/der338

4. Palomba S, Santagni S, Falbo A, La Sala GB. Complications and challenges associated with polycystic ovary syndrome: current perspectives. Int J Womens Health 2015;7:745-63. https://doi.org/10.2147/JWH.S703।4

5. Azziz R. Diagnosis of Polycystic Ovarian Syndrome: The Rotterdam Criteria Are Premature. J Clin Endocrinol Metab 2006;9I(3):78I-5. https://doi.org/10.1210/jc.20052153

6. Nuttall FQ. Body Mass Index: Obesity, BMI, and Health: A Critical Review. Nutr Today 2015;50(3): I I 728. https://doi.org//0.1097/ NT.0000000000000092

7. Bocéréan $C$, Dupret E. A validation of the Hospital Anxiety and Depression Scale (HADS) in a large sample of french employees. BMC Psychiatry 20|4;|4:354. https://doi.org/ |0.| | 86/s | 2888-0|4-0354-0

8. Mumford DB, Tareen IA, Bajwa MA, Bhatti MR, Karim R. The translation and evaluation of an Urdu version of the Hospital Anxiety and Depression Scale. Acta Psychiatr Scand |99|;83(2):8I-5. http://dx.doi.org/ 10.1 | I |/j.1600-0447.199|.tb07370.x

9. Knopfholz J, Disserol CC, Pierin AJ, Schirr FL, Streisky L. Validation of the friedewald formula in patients with metabolic syndrome. Cholesterol 20|4;20|4:26|878. http:// dx.doi.org/I0.I I55/20|4/26I878 
10. Sane R, Amin G, Dongre S, Mandole R. Evaluation of the lipid parameters in chronic heart failure patients and their correlation with body mass index. Int JAdv Med 2019;6(3):805-9. http://dx.doi.org/10.18203/23493933.ijam20192243

II.Luppa P, Brückner C, Schwab I, Hauck S, Schmidmayr S, Birkmayer C, et al. 7á-Biotinylated testosterone derivatives as tracers for a competitive chemiluminescence immunoassay of testosterone in serum. Clin Chem 1997;43(I2):2345-52. https://doi.org/ 10.1093/clinchem/43.12.2345

12. Zehra S, Arif A, Anjum N, Azhar A, Qureshi M. Depression and Anxiety in Women with polycystic Ovary Syndrome from Pakistan. Life Sci J 20I5; I2(3s): I-4.

13. Enjezab B, Eftekhar M, Ghadiri-Anari A. Association between severity of depression and clinico-biochemical markers of polycystic ovary syndrome. Electron Physician 20 17;9 (I I):5820-5. https://doi.org/ $10.19082 / 5820$

14. Chen X, Ni R, Mo Y, Li L, Yang D. Appropriate BMI levels for PCOS patients in Southern China. Hum Reprod 2010;25(5): I295-302. https://doi.org/10.1093/humrep/deq 028

15. Bilal M, Haseeb A, Rehman A.
Relationship of Polycystic Ovarian Syndrome with Cardiovascular Risk Factors. Diabetes Metab Synd 2018;12(3):375-80. https://doi.org/ I0.1016/j.dsx.2018.01.006

16. Wild RA, Carmina E, DiamantiKandarakis E, Dokras A, EscobarMorreale HF, Futterweit W, et al. Assessment of cardiovascular risk and prevention of cardiovascular disease in women with the polycystic ovary syndrome: a consensus statement by the Androgen Excess and Polycystic Ovary Syndrome (AEPCOS) Society. J Clin Endocrinol Metab 2010;95(5):2038-49. https://doi.org/10.1210/jc.2009. 2724

\section{AUTHOR'S CONTRIBUTION}

Following authors have made substantial contributions to the manuscript as under:

RH: Conception and study design, acquisition, analysis and interpretation of data, drafting the manuscript, critical review, approval of final version to be published

SUR: Conception and study design, critical review, approval of final version to be published

TZ: Acquisition of data, critical review, approval of final version to be published

MT: Acquisition of data, drafting the manuscript, approval of final version to be published

Authors agree to be accountable for all aspects of the work in ensuring that questions related to the accuracy or integrity of any part of the work are appropriately investigated and resolved.

\section{CONFLICT OF INTEREST \\ Authors declared no conflict of interest \\ GRANT SUPPORT AND FINANCIAL DISCLOSURE \\ Authors have declared no specific grant for this research from any funding agency in the public, commercial or not-for-profit sectors}

\section{DATA SHARING STATEMENT}

The data that support the findings of this study are available from the corresponding author upon reasonable request.

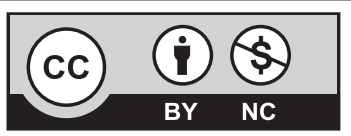

This is an Open Access article distributed under the terms of the Creative Commons Attribution-Non Commercial 2.0 Generic License.
KMUJ web address: www.kmuj.kmu.edu.pk

Email address: kmuj@kmu.edu.pk 